\title{
STIMULATED RELEASE OF ARACHIDONATE AND PROSTAGLANDINS IS VECTORIAL IN MDCR EPITHELIAL CELLS
}

\author{
A.M. Cortizo**, J.M. Besterman, P.P. Leitner \\ and $K . A$. Chandrabose
}

\begin{abstract}
Glaxo Inc. Research Institute, Five Moore Drive, Research Triangle Park, North Carolina, 27709 - "Cenexa, (Centro de Endocrinologia Experimental y Aplicada) UNLP-Conicert. Facultad de Cienclas Medicas, UNLP, Argentina - "AMC Is A Member of The Carrer del Investigator, CIC Provincia de Buenos Aires, Argentina.
\end{abstract}

\section{Abstract :}

The receptor mediated activation of phospholipase $A_{2}$ by appropriate ligands results in the synthesis and release of eicosanoids, a class of potent bioregulatory molecules. Madin-Darby canine kidney cells (MDCK) are polarized epithelial cells, with structurally and functionally distinct plasma membrane domains separated by tight junctions. Using MDCK cells grown in dual sided chambers, we show in this report, that a) the receptor mediated release of prostaglandins and arachidonate into the extracellular medium is predominantly unidirectional, b) the direction of release is agonist specific, and c) the magnitude of the response due to a given agonist is cell-domain specific. These characteristics, if operative in vivo, would contribute towards the optimal function of trans-cellular metabolism of eicosanoids already demonstrated.

\section{Introduction:}

Madin-Darby canine epithelial cells have been extensively used to study epithelial polarity and membrane sorting processes in mammalian cells growing in specialized culture environments. When appropriately grown in cell culture systems, these cells exhibit properties characteristic of polarized epithelial cells in culture. They grow forming a tightly sealed monolayer and show the expected structural and functional polarity (1-6). There is considerable evidence to show that MDCK cells sort out newly synthesized apical and basolateral plasma membrane proteins intracellularly and then transcytose them to correct plasma membrane domains (7-12). The resulting asymmetrical distribution of functional molecules in the membrane will dictate the nature of polarized behavior exhibited by the cells (13-15). 
Eicosanoids are physiological response modulators which act in both autocrine as well as in paracrine fashions on target cells $(16,17)$. An eicosanoid synthesized in one cell has been shown to be the substrate for metabolic transformations by another cell type in more than one biological system (18-24). Such transcellular metabolic routes are conceivably most effective if the secretion is vectorially focussed in a polarized manner from one cell to another. MDCK cells synthesize and secrete relatively large quantities of prostaglandins (PGs), and have been used to study the roles played by $\mathrm{PGs}$ in various cellular functions (25-27). In this report we have used MDCK cells to study the nature and consequences of epithelial polarity when the cells are stimulated to produce and release arachidonate (AA) and its PG metabolites.

Materials and methods:

$\left[5,6,8,9,11,12,14,15^{3} \mathrm{H}\right] \mathrm{AA}$ with specific activity $230 \mathrm{Ci} / \mathrm{mmol}$ and uniformly labeled [ ${ }^{14} \mathrm{C}$ ] sucrose with specific activity of $540 \mathrm{mCi} / \mathrm{mmol}$ were purchased from Amersham. Bradykinin and PG standards were from Sigma. Ionomycin was purchased from Calbiochem; ATP- $\gamma-\mathrm{S}$ was from Boehringer Mannheim, and $24 \mathrm{~mm}$ Transwell plates with ( 0.4 micron pore size) polycarbonate filters were from Costar, Cambridge, MA.

Cell Culture:

MDCK cells (ATCC CCL.34) were grown in $75 \mathrm{~cm}^{2}$ tissue culture flasks in DMEM supplemented with $10 \%$ fetal calf serum. After reaching confluency, the cells were prepared by trypsinizing and plating them at low density on to the polycarbonate filter of the transwell plates. The number of cells plated per well were adjusted so that the monolayer would have to divide at least 34 times to reach saturation density. The media was changed to contain $0.5 \%$ serum in both chambers of the transwell 24 hours before the experiments were begun. 
Measurement of AA and PGs:

${ }^{3}[\mathrm{H}] \mathrm{AA}$ and its released metabolites were extracted from the medium and analyzed as previously reported (28). When PGs in the medium were not quantitated, AA release was taken to be the total $\mathrm{cpm}$ released into the medium. This assumption is justified, since the contribution of cpm from the $P G$ products under these conditions is negligible when compared to the $\mathrm{cpm}$ contained in AA. (Fig. 6).

Results:

To verify that the dual-chambered transwell model is an adequate experimental system to detect and quantitate vectorial release of metabolites, the following experiments were performed. Cells were grown into a confluent monolayer on the filter as described in Materials and Methods. The tightness of the monolayer to passive diffusion of sucrose or AA was tested as described in the legends of Fig. 1A and 1B, respectively.

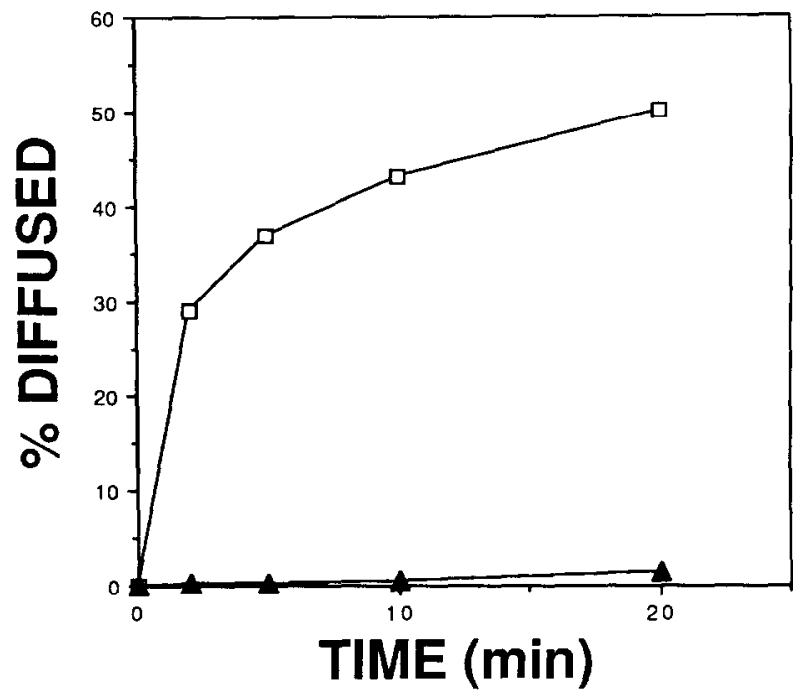

FIG. 1A. Diffusion of sucrose across the empty transwell filter or confluent monolayer of MDCK cells. $\left[{ }^{14} \mathrm{C}\right]$ sucrose was added to the apical (top) chamber of the transwell in the absence (open square) or presence of a confluent monolayer of MDCK cells (filled triangle). The basolateral (bottom) chamber was sampled at the indicated times. Results are expressed as the percent of the total dpm appearing in the basolateral chamber. 


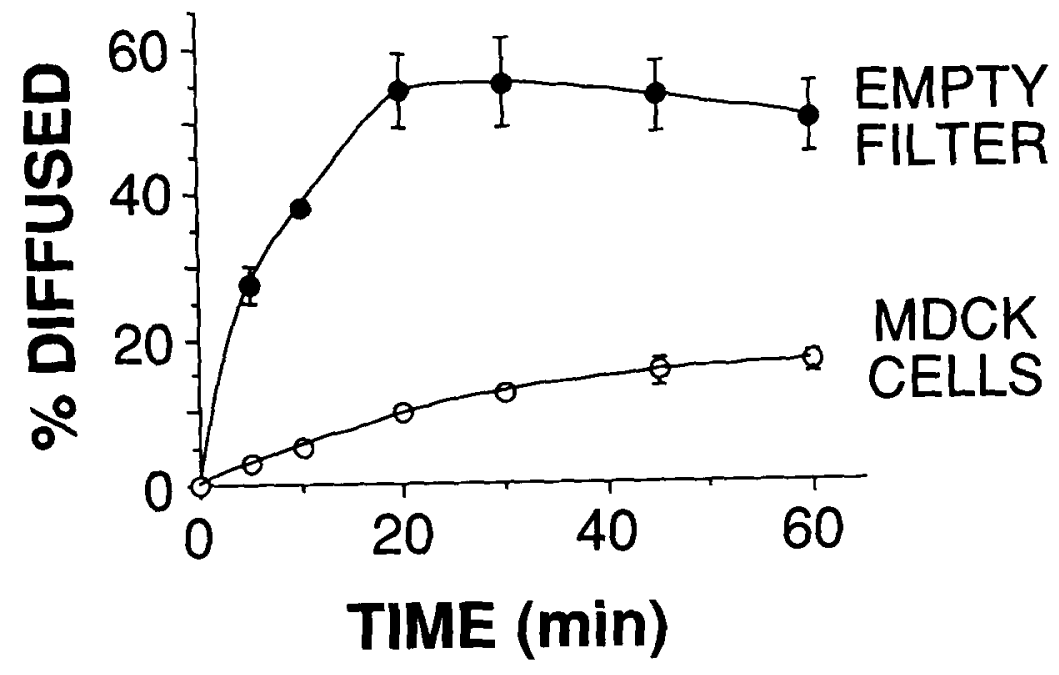

FIG. 1B. Diffusion of added AA across the empty transwell filter or confluent monolayer of MDCK cells. [ $\left.{ }^{3} \mathrm{H}\right] \mathrm{AA}$ was added to the apical or basolateral side of the transwell, with (open circle) or without (filled circle) a confluent monolayer MDCK cells. Basolateral or apical wells were sampled at the indicated intervals. The diffusion index of a given well is expressed as the percent of the total counts added to the opposite well at zero time. 
From the data presented in Figures $1 \mathrm{~A}$ and $1 \mathrm{~B}$ the following conclusions may be drawn: a) the rate of diffusion of sucrose or AA through a confluent cell monolayer of MDCK cells in a transwell is a slow process compared to the rates observed for their diffusion across the filter alone, $b$ ) in the presence of a MDCK cell monolayer, there is negligible mixing of the contents of the apical and basolateral wells up to 30 minutes of incubation.

Additional experiments using a variety of agonists indicated that the time course of release of AA was linear when the stimulation was restricted to five minute periods (data not given). The basal release without added agonists was reproducible, averaging close to the cpms given in the legend of Fig. 2. In the experiments described below, unless otherwise stated, the release is expressed as fold increase over the basal, since the basal release was comparable to that given in the legend of Fig. 2.

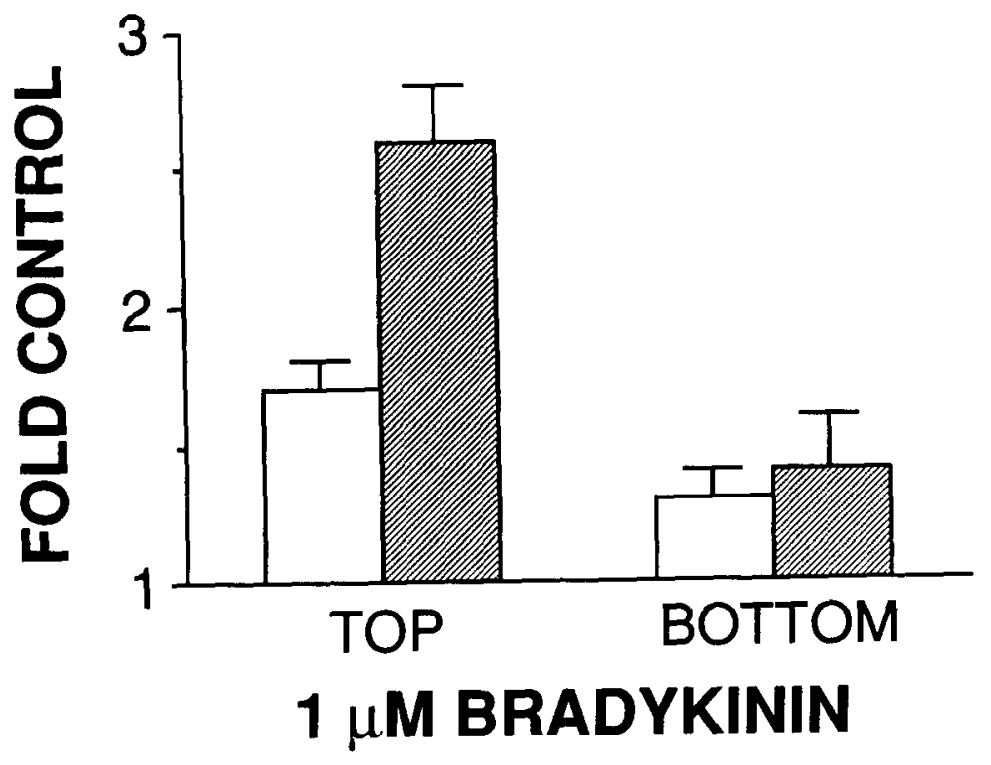

Fig. 2. Polarized AA release in response to bradykinin. MDCK cells were pre-labeled for $16 \mathrm{hrs}$ with ${ }^{3}[\mathrm{H}] \mathrm{AA}$, rinsed and incubated with bradykinin at $10^{-6} \mathrm{M}$ in DMEM at $37^{\circ} \mathrm{C}$ for five min. After the addition of the agonist to the indicated side of the transwell (top meaning apical, bottom meaning 
basolateral), aliquots of media were collected from both the apical (open bar) and the basolateral (striped bar) and quantitated. The release for five min, without added agonist, was $5000 \pm 612 \mathrm{cpm} / \mathrm{ml}$ of medium.

Bradykinin is a well documented peptide agonist for the stimulation of phospholipase $A_{2}$ and $P G$ release $(29,30)$. Using bradykinin as an activator of phospholipase $\mathrm{A}_{2}$, several novel features which characterize the stimulated release of AA are evident in the experiments described, due to the epithelial polarity of the MDCK cells. Fig. 2 shows the effect of 5 min. of stimulation of the cells, with bradykinin added either from the apical or the basolateral side of the transwell.

Note that not only is the extent of stimulation five fold higher when the peptide is added from the apical well, almost all of the AA released is predominantly secreted into the basolateral compartment of the transwell. Thus, in cells showing epithelial polarity, the agonist receptor interaction may be side-specific (apical vs basolateral), and the secretion of the interaction product ( $\mathrm{AA}$ in this case) is vectorially directed. Interestingly, the direction of secretion is opposite to that of the side to which the agonist was added.

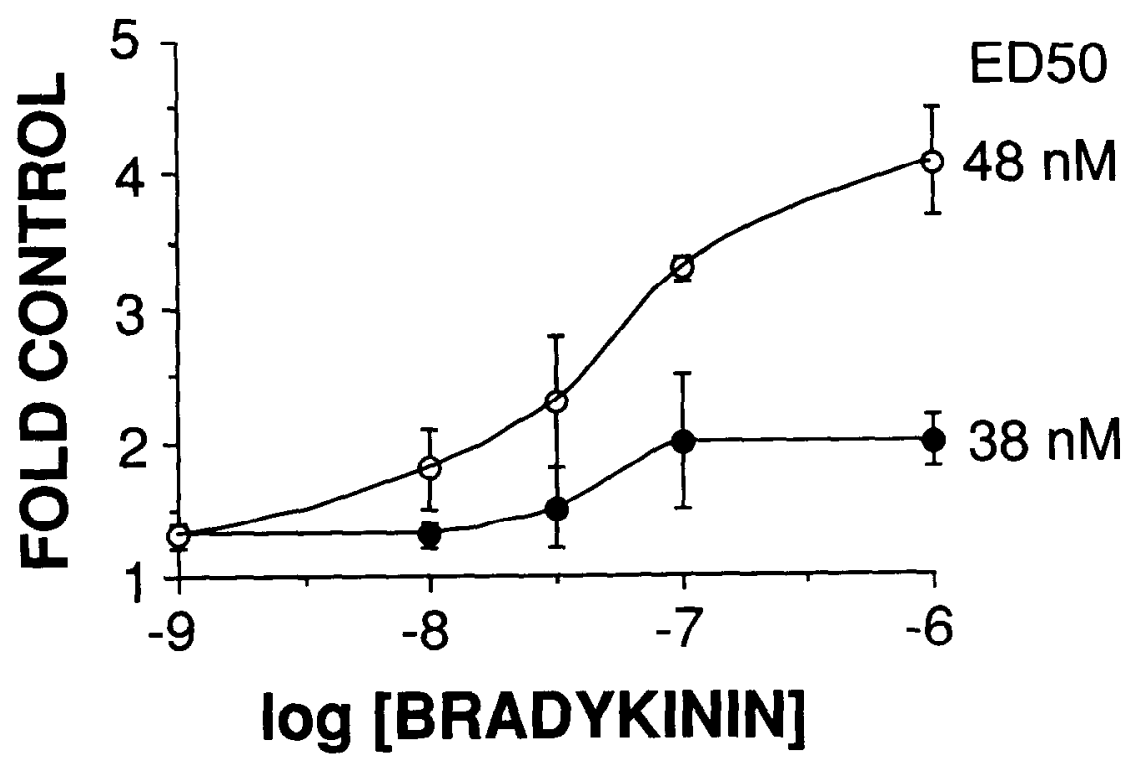

Fig. 3. Dose-response of bradykinin for AA release in MDCK cells. The cells were prepared and treated for a five min. period, as described in the legend for Fig. 2. The agonist was added from the apical well. Aliquots of media were collected and counted from apical (filled circle) and basolateral (open circle) wells. 
Fig. 3 depicts the dose-response to bradykinin. Since the ability of the cells to release AA was shown (Fig. 2) to be maximal when bradykinin was added from the apical side of the cell, the dose response for this agonist was measured only with the agonist added to the apical side of the cell. The maximal and minimal responses were obtained between concentrations ranges of $10^{-6}$ to $10^{-9} \mathrm{M}$ bradykinin. Throughout this concentration range, the release was found to be vectorial with about two fold more AA released into the basolateral well, at each concentration of the agonist used. However, the $\mathrm{ED}_{50}$ of bradykinin for $\mathrm{AA}$ release on both sides were approximately equal, $38 \mathrm{nM}$ for apical vs $48 \mathrm{nM}$ for basolateral.

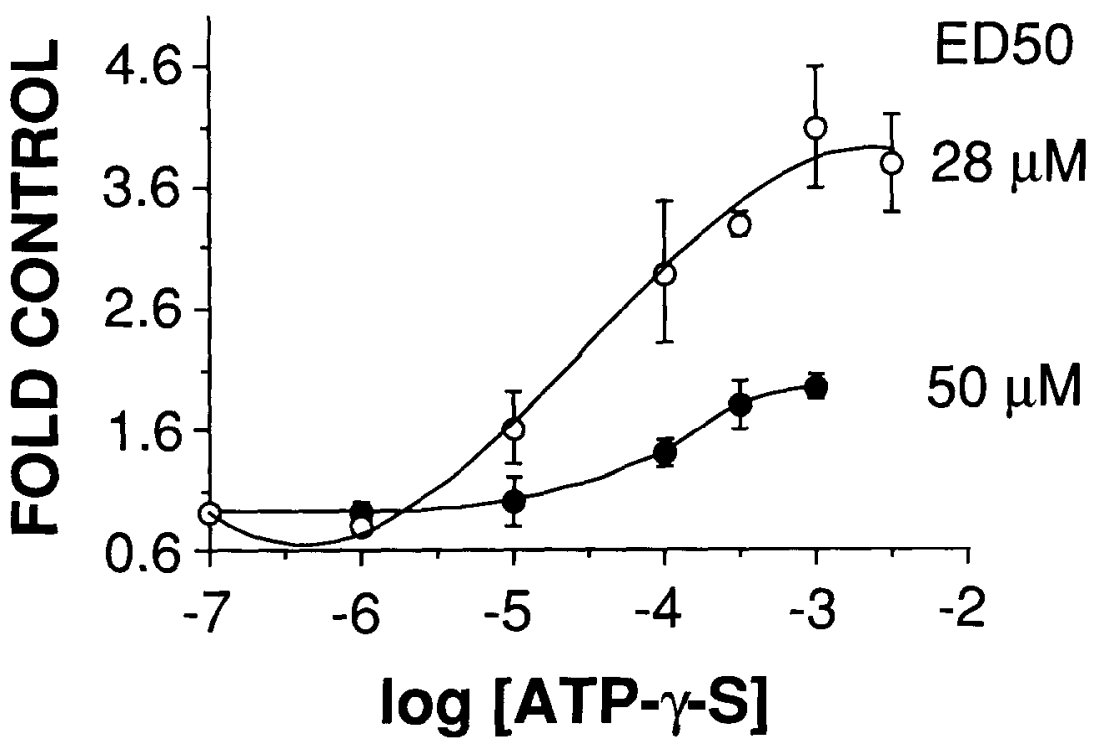

Fig. 4. Dose-response for AA release with ATP- $\gamma-S$ in MDCK cells. Cells were grown and treated with ATP- $\gamma$-S according to the protocol of the legend given in Fig. 2. The agonist was added from the apical side, and incubated for five mins. Aliquots were counted from apical (filled circle) and basolateral wells (open circle). 
ATP has been shown to stimulate phospholipase activity and PG production by interacting with the purinergic receptors of the target cells (31). The experiments described were repeated using ATP- $\gamma$-S as the agonist. Similar to bradykinin, the ATP- $\gamma-S$ added from the basolateral side failed to release appreciable quantities of AA (data not given). The dose response of ATP- $\gamma$-S for release of AA to both sides of the cells is shown in Fig. 4. A seven-fold increase in release of AA may be observed in this experiment at the maximal dose of the agonist used. The secretion of AA is vectoral, directed primarily from the basolateral side of the cells. The $\mathrm{ED}_{50}$ for ATP- $\gamma-\mathrm{S}$ for the release of AA to both sides were of similar magnitude, $28 \mu \mathrm{M}$ for basolateral vs $50 \mu \mathrm{M}$ for the apical side.

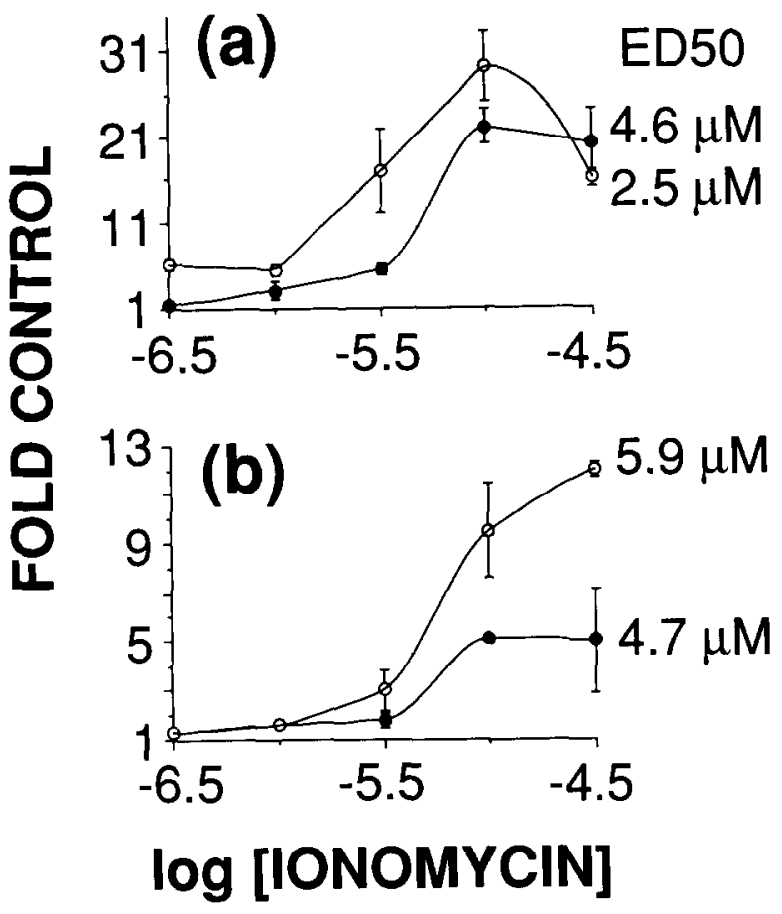

Fig. 5. Dose response for ionomycin for AA release in MDCK cells. The cells were prepared and treated with ionomycin according to the protocol given in the legend of Fig. 2. Fig. 5a shows the release when the agonist was added from the apical well. Fig. $5 \mathrm{~b}$ represents addition of ionomycin from the basolateral well. After five mins of incubation with the cells, aliquots of media were collected from the apical (filled circle) and basolateral wells (open circle) and counted. 
In Fig. 5, dose-response data is given for ionomycin, employing the same protocol described for bradykinin and ATP- $\gamma-S$. The activation of phospholipase $\mathrm{A}_{2}$ by ionomycin is mediated by $\mathrm{Ca}^{++}$ions - a different mechanism (32) from that of the receptor mediated activation of the enzyme, described for bradykinin and ATP- $\gamma-\mathrm{S}$. Appreciable release of AA was observed with ionomycin, when added either from apical side (Fig. 5a) or from basolateral side (Fig. 5b). However, the release was significantly vectorial, but only when the agonist was added from the basolateral side. In this case about 10 fold more AA was released into the basolateral side compared to the apical side, at the maximal concentration of the agonist used (Fig. 5b). Regardless of the side of addition, the $\mathrm{ED}_{50}$ of ionomycin for $\mathrm{AA}$ release was of the same order of magnitude (Fig $5 \mathrm{a}$ and Fig $5 \mathrm{~b}$ ), for both apical and basolateral compartments of the transwell.

In experiments described below, the media was collected after addition of a variety of stimulating agents and processed by TLC (28) to quantify the AA and eicosanoids present in the apical and basolateral compartments of the cells.

Fig. 6 is the reproduction of an autoradiograph, after fluorography of the TLC plate used to separate AA and its metabolic products. The results show that when thrombin is used to stimulate the cells, addition from the apical side is far more effective in the synthesis and release of PGs (lanes 1-4) from the released AA. The release of PG products show a high degree of polarity. Most of the PGs synthesized are secreted to the apical side of the transwell (lane 3). Considerable amounts of AA are released to the basolateral well when thrombin is added from the basolateral side. However, very little PG products are synthesized from the liberated AA (lanes 1-2).

Results shown in lanes 5-8 demonstrate that trypsin is effective in AA release and $P G$ production when added from either side of the transwell. However, clear polarity of secretion is apparent with most of the $P G$ products directed to the apical side of the transwell (lanes 5,7,8, and 11). Lanes 9-12 show that the synthesis of PGs is dependent on the concentration of the agonist, but the direction of polarity is independent of the dose of the agonist. 


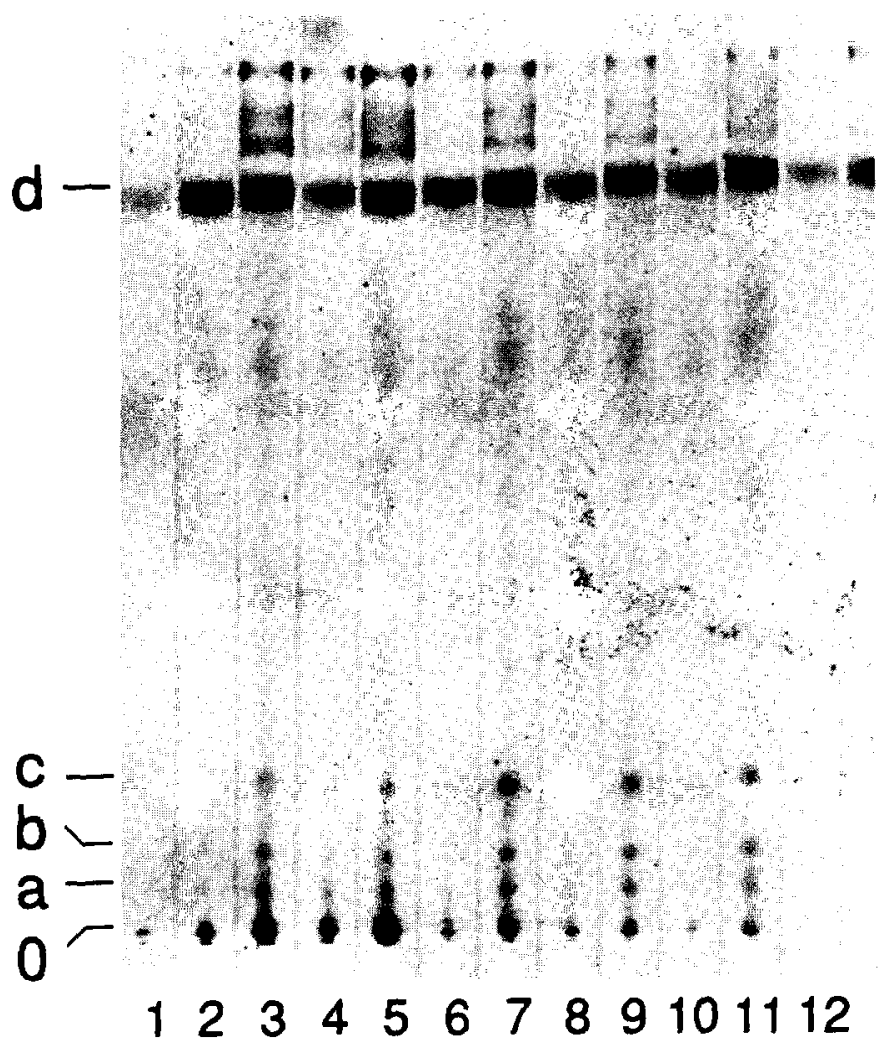

Fig. 6. Fractionation of lipids by TLC. MDCK cells were pre-labeled, and treated with thrombin and trypsin at concentrations indicated below. After five min. of incubation with the agonists, aliquots of media were collected and processed for TLC, as described in the reference (28). Lanes 1-4. Thrombin at $1.0 \mathrm{unit} / \mathrm{ml}$, added to the basolateral (lanes 1,2) or to the apical (lanes 3,4) well. Media were sampled from the apical (lanes 2, 3) and from the basolateral wells (lanes 1, 4). Lanes 5-8. Trypsin at $250 \mu \mathrm{gms} / \mathrm{ml}$ added to the basolateral $(5,6)$ or to the apical $(7,8)$ well. Lanes $(5,7)$ are apical well samples, lanes $(6,8)$ are basolateral well samples. Lanes 9-12. Trypsin at 25 $\mu \mathrm{gms} / \mathrm{ml}$ was added to the basolateral (lanes 9,10 ) or to the apical (lanes $11,12)$ well, Lanes $(9,11)$ are apical well samples, and lanes $(10,12)$ are basolateral well samples. Bands are identified as follows by cochromatography with standards. $\mathrm{O}=$ Origin, $\mathrm{a}=\mathrm{PGI}_{2}, \mathrm{~b}=\mathrm{PGF}_{2} \alpha, \mathrm{c}=$ $P G E_{2}, d=A A$. Bands with $R f>d$ were identified as neutral glycerides and cholesterol esters. 


\section{Discussion:}

MDCK cells have been extensively used in in vitro studies to understand the nature of polarity in epithelial cells (1-6). To our knowledge this is the first report investigating polarized secretion of $A A$ and its eicosanoid products in stimulated epithelial cells. We have used agonists belonging to three different classes - based on their known mechanisms of stimulation - for eicosanoid production and release by the cells. These are: a) stimulation of cells by peptide agonists (bradykinin, thrombin, trypsin); b) stimulation by a non-peptide agonist which interacts with specific receptors (ATP- $\gamma$-S for purigenic receptors) and c) the $\mathrm{Ca}^{++}$mediated direct activation of phospholipase $\mathrm{A}_{2}$ (ionomycin).

The results show that depending on the agonist used, the secretion of the metabolites produced as a results of the stimulation is vectorial in nature. Furthermore, the direction of polarization (whether release is directed to the apical or basolateral wells) is agonist specific. Thus, with bradykinin, ATP- $\gamma$ $\mathrm{S}$, and ionomycin, the release of liberated AA is predominantly to the basolateral side of the cells. The eicosanoids synthesized (with trypsin and thrombin) are also secreted by the cells in a clearly vectorial manner, but this secretion of PGs is directed to the apical well. Collectively, the data show a) the vectorial nature of release of $\mathrm{AA}$ and its metabolites in MDCK epithelial cells, and b) agonist specificity for the direction of the vector. It should be noted, however, that the present studies using cells radiolabeled with arachidonic acid do not measure arachidonate mass released and may favor a rapidly turnover pool of arachidonate which may be sequestered to specific membrane domains.

Another interesting feature of the stimulus coupling process revealed by this study is the "sidedness" of epithelial cells. In the case of bradykinin, ATP- $\gamma-S$, and ionomycin, the extent of activation, measured as AA release, is clearly dependent on the side to which the agonist was added. The "sidedness" is best illustrated by the results of the experiments with ionomycin. Ten fold higher concentration of ionomycin was required to elicit the same response when applied from the basolateral side of the cells as compared to the addition of this reagent to the apical well.

The measured $\mathrm{ED}_{50}$ of the agonists were all of the same order of magnitude. Thus, it appears that the affinity of the receptors are not measurably different regardless of the side on which they are present. Therefore, the large differences in responses observed may be attributed to the numbers of limiting critical molecules present on either side of the cells. Whatever is the explanation, the responses observed appears to be clearly domain specific with a given agonist.

The data given in this report suggest structural differences between membrane domains, which in turn confer functional differences leading to 
specific secretory patterns of metabolites. Published literature on MDCK cells presents convincing evidence for epithelial sorting of membrane components and a barrier to diffusion of proteins and lipids, as long as the tight junctions remain intact in these cells $(1,3,5)$. These characteristics of MDCK cells provide adequate explanation for the observed pattern of secretion of AA and PGs reported here. In MDCK cells, phosphatidylcholine has been shown to be predominantly localized in the basolateral membrane (33). In bradykinin induced phospholipase activation, phosphatidylcholine has been claimed to be the source of the released AA (30). If this assumption is correct, it follows that the membrane domains enriched with phosphatidylcholine will be the source for the AA deacylated with bradykinin. Since the released AA cannot diffuse uniformly across the tight junctions of the cell, this reaction product will be secreted vectorially from the basolateral side of the cell. Membrane sorting might also result in a functionally optimal but topographically asymmetrical segregation of components of the transductional apparatus (7-15). The receptors, $G$ proteins, and target enzymes, (phospholipases and PG synthase in this case) might also be enriched in a domain specific fashion, due to sorting and transcytosis $(8,10,11,13)$. The magnitude of the response of the cell to a given stimulus will be limited by the number of the relevant functional molecules segregated on the side to which the agonist is added, or the side with which it is capable of interacting. Thus, the agonist and domain specific responses reported here may be readily explained on the basis of epithelial polarity, arising from membrane sorting.

Do the observations reported here have any relevance in the physiological context of AA metabolism? If epithelial polarity exists in vivo it is not unreasonable to expect some physiologic significance for the observations reported here. Previous studies with endothelial cells and smooth muscle cells in co-culture demonstrated polarity to arachidonic acid metabolism and suggested that prostaglandin production by smooth muscle cells could occur in response to stimuli that caused arachidonic acid release from endothelial cells $(18,19)$. Stimulated platelets can provide arachidonate for metabolism by leukocyte lipoxygenases (20) and endo-peroxide substrates for vascular prostacyclin synthesis (21). Exchange of hydro-peroxy and hydroxy acids between platelets and neutrophils can lead to formation of new bioactive metabolites (22). Metabolism of neutrophil derived leukotriene $\mathrm{A}_{4}$ by erythrocytes (24), platelets (34) and mast cells (35) have been reported. When taken together with findings in the literature documenting transcellular metabolism of AA derived products, the following possibility does not appear to be an unreasonable one to suggest.

With close intercellular contact, as happens in platelet adhesion to vascular endothelium, the polarized release of metabolites such as reported here may be the most effective way to deliver substrates for the transcellular metabolism of AA derived compounds. Thus, optimal utilization of platelet derived endo-peroxide for prostacyclin synthesis, or the elaboration of a 
patho-physiologic mediator (36) by transcellular metabolism when neutrophils adhere to the endothelium of an injured vessel, could occur as a consequence of polarized secretion.

\section{REFERENCES:}

1) Dragsten, P.R., R. Blumenthal, and J.S. Handler. Membrane asymmetry in epithelia: is the tight junction a barrier to diffusion in the plasma membrane? Nature 294:718, 1981.

2) Madara, J.L. Intestinal absorptive cell tight junctions are linked to cytoskeleton. Am. J. Physiol. 253:C171, 1987.

3) Gonzalez-Mariscal, L.B., Chavez de Ramirez, and M. Cereijido. Tight junction formation in cultured epithelial cells (MDCK). J. Membrane Biol. 86:113, 1985.

4) Gottlieb, T.A., G. Beaudry, L. Rizzolo, A. Coleman, M. Rindler, M. Adensik, and D.D. Sabatini. Secretion of endogenous and exogenous proteins from polarized MDCK cell monolayers. Proc. Natl. Acad. Sci. USA. 83:2100, 1986.

5) Kondor-Koch, C., R. Bravo, S.D. Fuller, D. Cutler, and H. Garoff. Exocytic pathways exist to both the apical and basolateral cell surface of the polarized epithelial cell MDCK. Cell. 43:297, 1985.

6) Le Bivic A., M. Hirn, and H. Reggio. HT-29 cells are in vitro model for the generation of cell polarity in epithelia during embryonic differentiation. Proc. Natl. Acad. USA. 85:136, 1988.

7) Bartles, J.R., and A.L. Hubbard. Plasma membrane protein sorting in epithelial cells. Do secretory pathways hold the key? TIBS. 13:18, 1988.

8) Caplan, M.J., H.C. Anderson, G.E. Palade, and J.D. Jamieson. Intracellular sorting and polarized cell surface delivery of $\left(\mathrm{Na}^{+} \mathrm{K}^{+}\right)$ A'TPase, an endogenous component of the MDCK cell basolateral plasma membrane. Cell. 46:623, 1986.

9) Caplan, M.J., J.L. Stow, A.P. Newman, J. Madri, H.C. Anderson, M.G. Farquhar, G.E. Palade and J.D. Jamieson. Dependence on $\mathrm{Ph}$ of polarized sorting of secreted proteins. Nature. 329:632, 1987.

10) Maratos-Flier, E., Ch-Y, Y. Kao, E.M. Verdin, and G.L. King. Receptor mediated vectorial transcytosis of epidermal growth factor by MardinDarby canine kidney cells. J. Cell. Biol. 105:1595, 1987.

11) Lombardi, T., R. Montesano, A. Wohlwend, M. Amherdt, J.D. Vassalli, and L. Orci. Evidence of polarization of plasma membrane domains in pancreatic endocrine cells. Nature 313:694, 1985.

12) Gottlieb, T.A., A. Gonzalez, L. Rizzolo, M.L. Rindler, M. Adesnik, and D.D. Sabatini. Sorting and endocytosis of glycoproteins in transfected polarized epithelial cells. J. Cell. Biol. 102:1242, 1986.

13) Rodriguez-Boulan, E. Membrane biogenesis, enveloped RNA viruses, and epithelial polarity. In: Modern Cell Biology. Vol. 1. (B.H. Satir, ed.) Alan R. Liss, Inc., 1983, p. 119. 
14) Simons, K. and S.D. Fuller. Cell surface polarity in epithelia. Annu. Rev. Cell Biol. 1:243, 1985.

15) Matlin, $K$. The sorting of proteins to the plasma membranes in epithelial cells. J. Cell Biol. 103:2565, 1986.

16) Salmon, J.A. Role of arachidonic acid metabolites in inflammatory and thrombotic processes. Biochem. Soc. Trans. 15:324, 1987.

17) Needleman, P. Prostacyclin in blood vessel-platelet interactions: perspectives and questions. Nature 279:14, 1979.

18) Shasby, D.M., L.L. Stoll, and A.A. Spector. Polarity of arachidonic acid metabolism by bovine aortic endothelial cell monolayers. Am.J. Physiol. 253:H1177, 1987.

19) Stoll, L.L. and A.A. Spector. Lipid transfer between endothelial and smooth muscle cells in coculture. I. Cell Physiol. 133:103, 1987.

20) Fiore, S. and C.N. Serhan. Formation of lipoxins and leukotrienes during receptor-mediated interactions of human platelets and recombinant human granulocyte/macrophage colony-stimulating factorprimed neutrophils. J. Exp. Med. 172:1451, 1990.

21) Marcus, A., B. Weksler, E.A. Jaffe, and M.J. Broekman. Synthesis of prostacyclin from platelet derived endoperoxides by cultured human endothelial cells. J. Clin. Invest. 66:979, 1980.

22) Maclouf, J., B. Fruteau de Laclos, and P. Borgeat. Stimulation of leukotriene biosynthesis in human blood leukocytes by platelet-derived 12-hydroperoxy-eicosatetraenoic acid. Proc. Natl. Acad. Sci. USA. 79:6042, 1982.

23) Marcus, A., M. Broekman, M.L. Safier, H. Ullman, N. Islam, C. Serhan, L. Rutherford, H. Korchak, and G. Weissman. Formation of leukotrienes and other hydroxy acids during platelet-neutrophil interactions in vitro. Biochem. Biophys. Res. Commun. 109:130, 1982.

24) McGee, J.E., and F.A. Fitzpatrick. Erythrocyte-neutrophil interactions. Formation of leukotriene $\mathrm{B}_{4}$ by transcellular biosynthesis. Proc. Natl. Acad. Sci. USA. 83:1349, 1986.

25) Levine, L., and A. Hassid. Epidermal growth factor stimulates prostaglandin biosynthesis by canine kidney (MDCK) cells. Biochem. Biophys. Res. Commun. 76:1181, 1977.

26) Levine, L., and Ohuchi. Retinoids as well as tumor promoters enhance deacylation of cellular lipids and prostaglandin production in MDCK cells. Nature. 276:274, 1987.

27) Lin, M.C., S.M. Wang, and S.K. Beckner. Induction of glucagon receptors and responsiveness in transformed kidney cells by prostagladins. In: Prostaglandins and Related Lipids Vol. 2. Alan R. Liss, Inc., New York, 1982, p. 493.

28) Chandrabose, K.A., R. Pottahil, D.J. Lang, and P. Cuatrecasas. Interferon resistant cell line lacks fatty acid cyclooxygenase activity. Science 212:239, 1981.

29) Needleman, P. Peptide induced prostaglandin biosynthesis in the renal vein constricted kidney. Biochem. J. 198(2):675, 1981. 
30) Burch, R.M. and J. Axlerod. Dissociation of bradykinin induced prostaglandin formation from phosphatidyl inositol turnover in Swiss $3 T 3$ fibroblasts. Evidence for $\mathrm{G}$ protein regulation of phospholipase $\mathrm{A}_{2}$. Proc. Natl. Acad Sci. USA 84:6374, 1987.

31) Forseberg, E.J., G. Fluerstein, E. Shohami, and H.B. Pollard. ATP stimulates inositol phospholipid metabolism and prostacyclin formation in adrenal medullary epithelial cells. Proc. Soc. Natl. Acad. Sci. USA 84:5630, 1987.

32) Bonner, F., and W.D. Stein. Calcium binding protein facilitates the intracellular diffusion for calcium pumping in distal convoluted tubule. Am. J. Physiol. 255:558, 1988.

33) Van Meer, G. and K. Simmons. The function of tight junctions in maintaining differences in lipid composition between the apical and basolateral cell surface domain of MDCK cells. EMBO J. 5:1455, 1986.

34) Feinmark, S.J. and P.J. Cannon. Endothelial cell leukotriene $C_{4}$ synthesis results from intercellular transfer of leukotriene $\mathrm{A}_{4}$ synthesized by polymorphonuclear leucocytes. I. Biol. Chem. 261:16466, 1986.

35) Dahinden, C.A., R.M. Clancy, M. Gross, J.M. Chiller, and T.E. Hugli. Leukotriene production by murine mast cells: evidence of a role for extracellular leukotriene $\mathrm{A}_{4}$. Proc. Natl. Acad. Sci. USA. 82:6632, 1985.

36) Vanderhoek, J.Y. Biological effects of hydroxy fatty acids. In: Biochemistry of Arachidonic acid metabolites. (W.M. Lands, ed.) Martinus Nijhoff, The Hague, Netherlands 1985, p. 213. 